\title{
Introduction of an innovative base isolation system for seismic protection of HV components based on a combination of wire ropes and viscous dampers
}

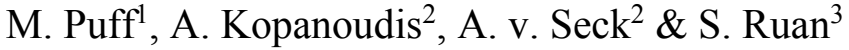 \\ ${ }^{1}$ ITT Control Technologies EMEA GmbH, Germany \\ ${ }^{2}$ Siemens AG, Germany \\ ${ }^{3}$ ITT Enidine Inc., USA
}

\begin{abstract}
Upstanding electrical high voltage (HV) equipment, such as the 3AP3 circuit breaker and similar, are structural systems where operators and manufacturers are still requesting a simpler, more robust and cost-effective base isolation solution in order to manage the qualification for high seismic requirements. This paper provides a summary of the methodology used to develop a reusable, optimized base isolated system in terms of structure based stress reduction and cost efficiency, which will attempt to achieve qualification safely. The methodology used in this study combines numerical analysis and shakes table testing in order to achieve a cost efficient solution. First, the analytical models for the structure and the base isolation system consisting of wire ropes and viscous dampers are created on a commercial FEM code. Once the models are calibrated, the system is optimized to achieve an optimum performance at minimum cost requirements. Finally, qualification through a shake table test takes place based on the given most suitable configuration. The ITT Enidine wire rope isolator was the most suitable solution for this type of structure and multiaxis earthquake excitation. In order to effectively control rocking mode amplitudes, supplementary viscous damping was added. The adjustability of the system makes it reusable for other single supporter $\mathrm{HV}$ components with different physical weights and geometry or lower seismic requirements.

Keywords: base isolation, seismic isolation, HV equipment, wire rope, viscous damper.
\end{abstract}




\section{Introduction}

Seismic protection of sensitive equipment in the energy distribution is essential to ensure a continuously electrical supply in all seismic areas of the world. Interruptions in power supply lead to an enormous damage of economy and the loss of essential infrastructures, such as power plants, water supply, waste water, telecommunication, etc.

This paper presents a base isolation concept used for critical equipment in power grids to ensure a stable electrical power supply during and after earthquake events. As one of the fundamental approaches in seismic protection, the idea of base isolation does decouple ground motions from the substructure by choosing soft mounts with low natural frequencies. Since low natural frequencies result in large movements and viscous dampers are added to limit dynamic deflections.

The methodology introduced is presented through the example of the 3AP3 circuit breaker developed by Siemens AG. The process however is not limited to equipment and damper type.

\section{Methodology}

A traditional approach of sizing and testing will be discussed first. By coupling the traditional approach with a finite analysis will show how to determine a cost optimized and at the same time best performing base isolation system for a $\mathrm{HV}$ circuit breaker. Figure 1 describes the approach.

1) Standard Approach of Development:

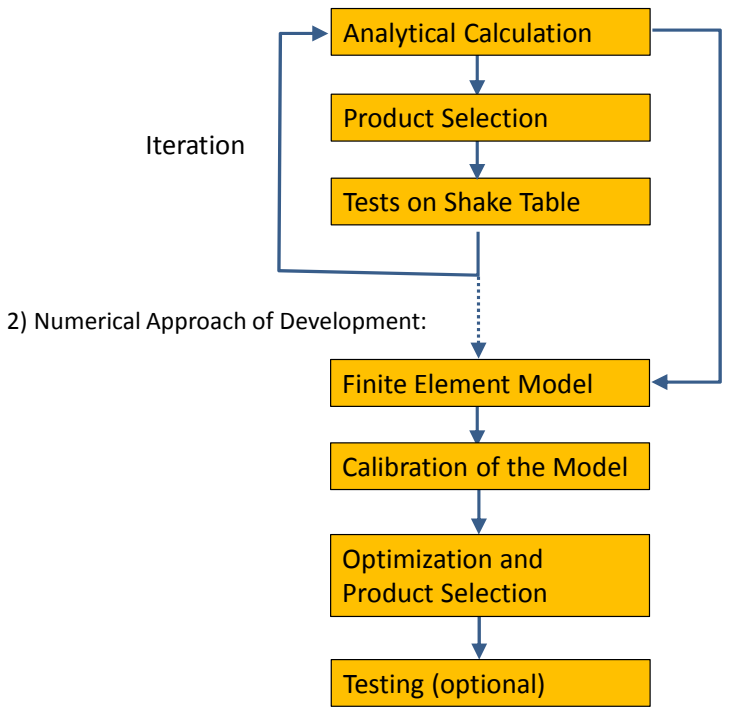

Figure 1: Methodology of qualifying equipment. 
Figure 1 shows the classic approach of analytical sizing and testing which can be repeated (see the first loop in figure 1). After performing the testing of the base isolated equipment the results can also be used for further numerical investigations and qualification of similar equipment (see the second loop in figure 1).

Scenario 1: The equipment with the selected base isolation system could not be qualified through the performed shake table test. The testing results can be used to develop a final solution without trial-and-error shake table testing by performing numerical analysis. This reduces the efforts and costs of excessive number of additional shake table tests.

Scenario 2: The equipment with the selected base isolation system is qualified through the performed shake table test and we want to use the results to develop a solution for higher seismic demands (e.g. a qualified system for moderate seismic level needs to be qualified for a higher level).

Scenario 3: The equipment with the selected base isolation system is qualified through the performed shake table test and we want to use the results to develop a solution for a qualification of similar type equipment (e.g. higher voltage or similar structure type).

Scenario 4: Cost optimization of qualified base isolated solution. If the qualified base isolated equipment has an unnecessary high safety margin, a cost effective solution can be achieved through optimization of the base isolation devices and the structure of the equipment itself.

\section{Analytical sizing of the base isolation system}

The base isolation system is based on a combination of wire ropes and viscous damper which are working in parallel [2]. For the preliminary sizing of both subcomponents in this section an analytical sizing approach is used.

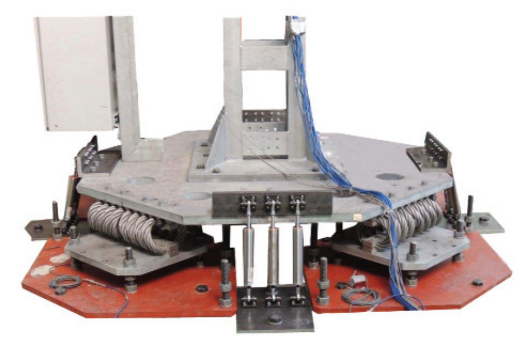

(a)

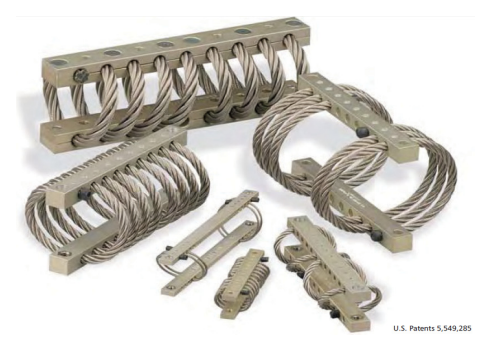

(b)

Figure 2: Base isolation system as a combination of wire ropes and viscous dampers (sources: (a) Siemens AG; (b) ITT). 


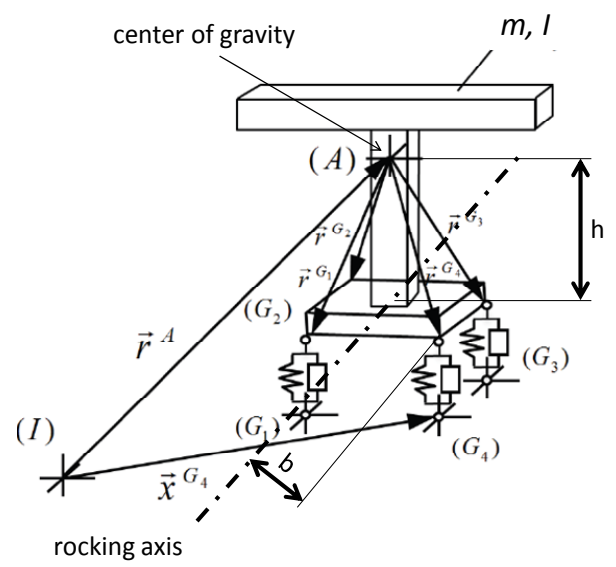

Figure 3: Rigid body model of circuit breaker for preliminary sizing of base isolation system (source of picture: ITT).

In a first step, a rigid body model (as shown in Figure 3) is defined. The main properties are considered as mass $m$, mass moment of inertia $I$ and geometry parameters. Due to the tall structure with high center of gravity the dominant mode is the rocking mode. The distance between rocking axis and center of gravity is defined by the variable $h$ (radius of gyration). Underneath the baseplate the wire rope damper system is placed. The main parameter per wire rope is the nonlinear stiffness $k(s)$, where the stiffness is a function of displacement $s$, and the distance $b$ between rocking axis and attachment point to the base plate. In this case the quantity of wire rope isolators is 4 units.

The rocking natural frequency of the equipment can be expressed as follows:

$$
f=\frac{1}{2 \pi} \sqrt{\frac{k_{r o t}}{I}}
$$

with the mass moment of inertia

$$
I=m \cdot h^{2}
$$

and the rotational stiffness

$$
k_{\text {rot }}=4 \cdot k(s) \cdot b^{2}
$$

Using the given system parameter for mass and position of center of gravity, which are fixed parameters anyway, the needed wire rope stiffness can be calculated. It is assumed that the first mode of rocking frequency should be located below $1 \mathrm{~Hz}$ to decouple the most seismic excitation frequencies which are mostly between 1 and $10 \mathrm{~Hz}$. 
The damping rate of the viscous damper is not considered for the basic sizing of the wire ropes. However it will be considered at the numerical analysis.

\section{Numerical analysis of the base isolation system}

\subsection{Used FEM environment}

The given analysis is carried out using a general purpose finite element program SAP2000 Nonlinear ver. 15.1.0 developed by Computer and Structures Inc., Berkeley, CA. By performing a Time History analysis in SAP2000, the nonlinear evaluation of the base isolated circuit breaker's dynamic structural response under earthquake loading can be obtained [3].

\subsection{Modelling of circuit breaker 3AP3}

The model is consisting of tri-dimensional assemblage of frame elements along with 2-D shell area elements with appropriate sectional and material properties in order to simulate the mass and stiffness characteristics of the circuit breaker. The detailed modelling of the base isolation devices is presented accordingly in section 4.3.

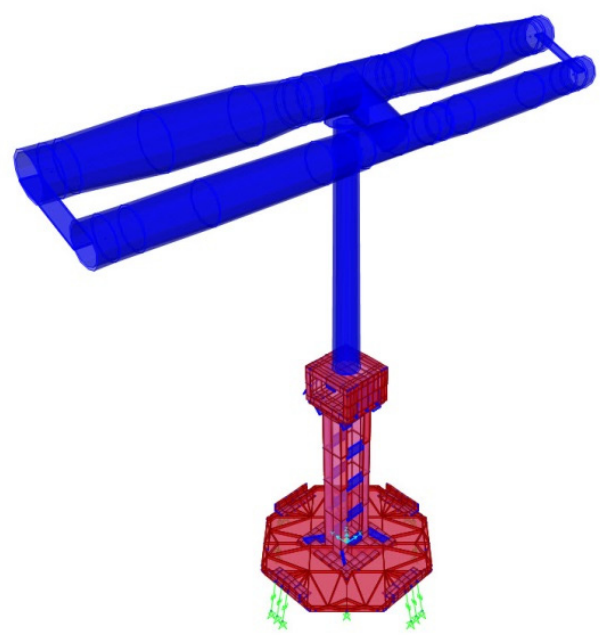

Figure 4: 3D aspect of the base isolated circuit breaker (SAP2000 extruded view, source of picture: Siemens AG).

\subsection{Modelling of wire rope isolators and viscous dampers}

\subsubsection{Modelling wire rope isolators}

Wire ropes are made from helical winded steel ropes which are working as 3D multidimensional springs with a higher stiffness in vertical direction and a low stiffness in horizontal direction. This behaviour is predestined for seismic 
protection since the static load of the equipment can be easily carried and the natural frequency in horizontal direction can be tuned in a low frequency range to achieve the best compromise of seismic isolation and limited deflections. As special feature the wire rope itself provides a certain number of damping which is coming from friction between the wires. For the simulation a measured dynamic force deflection curve of the selected wire rope model has been used to obtain the stiffness and damping properties. With this data the SAP 2000 simulation was parameterized. In difference to the physical equation based approaches, e.g. described in [4], a numerical polynomial approach was used for modelling the wire rope behavior.

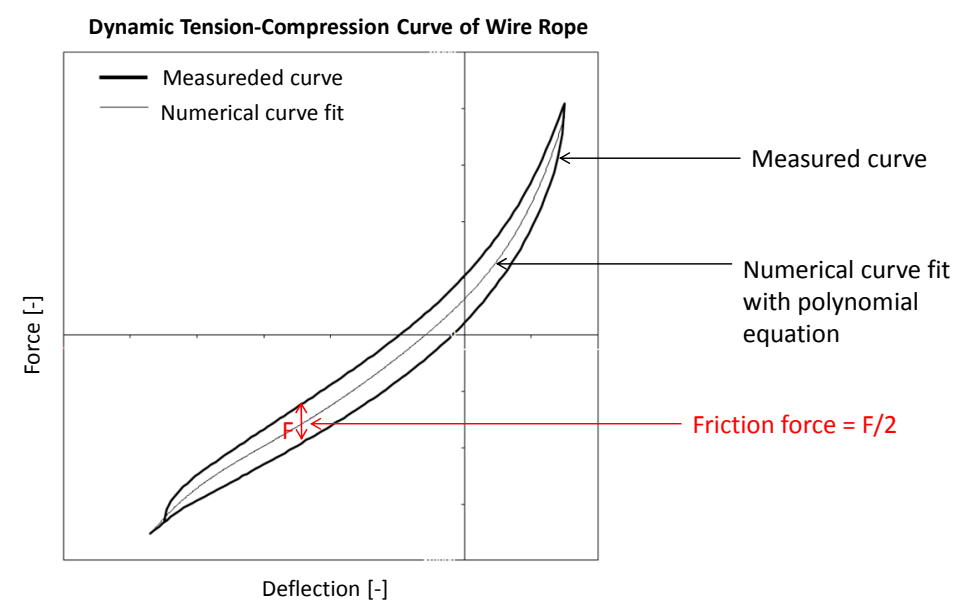

Figure 5: Wire rope modelling by numerical curve fit and friction force (source of picture: ITT).

\subsubsection{Modelling viscous damper devices}

Viscous damper are devices with a velocity dependent damping force which characteristics can be different in compression or extension direction. A special and customized orifice configuration and a fluid with a certain viscosity inside the dampers are used to guarantee the right damping ratio for fulfilling requirements for isolation and at the same time to limit deflections and keep stability of the equipment and its connected structures like flexible pipes or electrical wires. For modelling the viscous dampers an exponential approach is used:

$$
F=C \cdot v^{\alpha}
$$

The damping force is dependent on a constant $C$ and a velocity term with exponent $\alpha$. With different alpha terms smaller or larger than one a non-linear characteristic can be obtained. For alpha equal one the force velocity characteristic will be linear. The optimized alpha is determined by a numerical parameter variation in SAP 2000. 


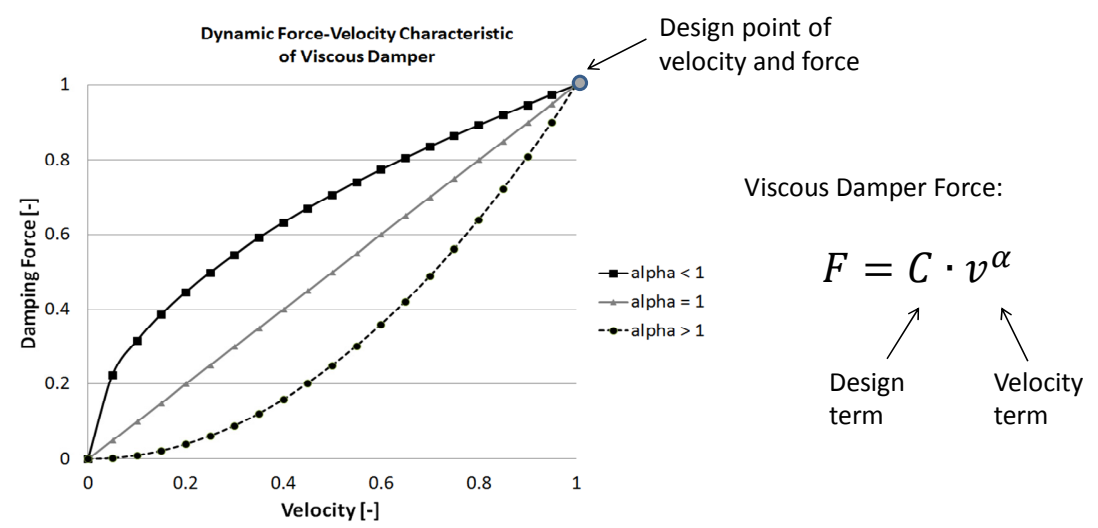

Figure 6: Viscous damper modelling by numerical exponential approach (source of picture: ITT).

\subsection{Calibration of FE model to test results}

Subsequent to the modelling of the circuit breaker (CB) and the base isolation system (combined wire ropes and viscous dampers), the model is checked and calibrated to known test results. These are obtained either specifically for the isolation devices alone from the ITT/Enidine factory tests, or for the combined base isolated CB from a performed shake table test. The response of each system/sub-system is compared to the FE model and refinements of the model take place to match the test results with accuracy.

\subsection{Optimization parameters of base isolation system}

For achieving the optimized solution according to the presented scenarios 1-4, see section 2, the following parameters can be modified:

\section{Base isolation}

- $\quad$ Type of wire ropes/viscous dampers;

- Number of viscous dampers;

- Position of wire ropers;

- Inclination of viscous dampers;

- Adjustment of dampers' characteristics (custom dampers);

- $\quad$ Base plate optimization.

\section{Equipment}

- Materials and sectional characteristics of structural parts;

- Additional reinforcements. 


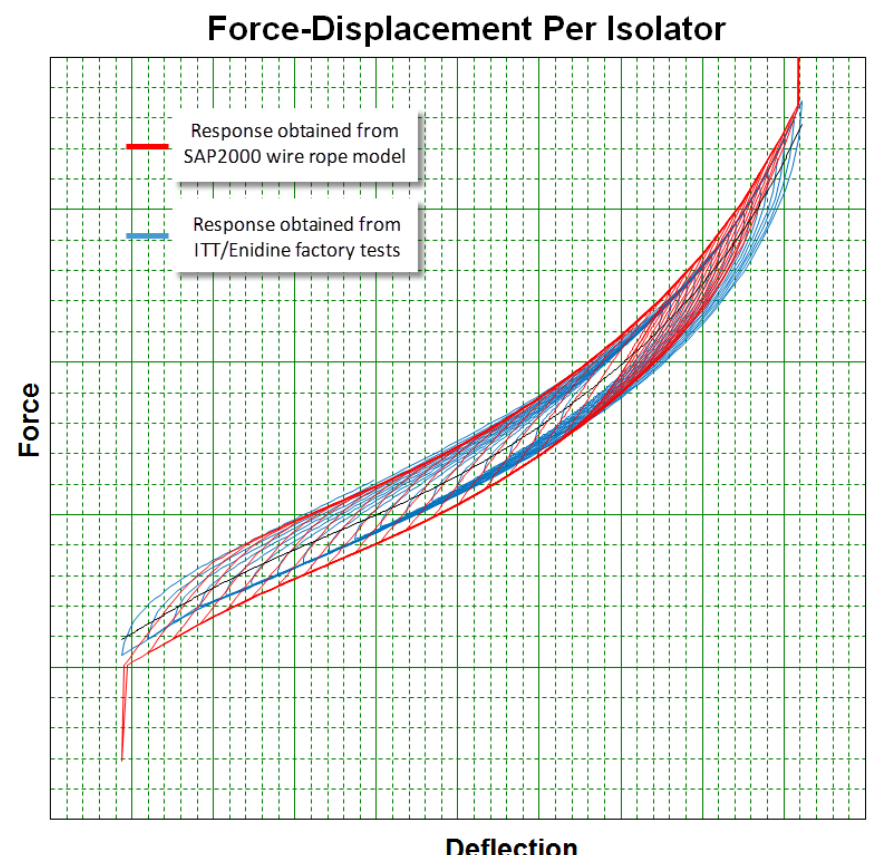

Figure 7: Single wire rope response. Comparison between SAP2000 modelled wire rope and ITT/Enidine factory test results (source of picture: Siemens AG).

\subsection{Results of numerical analysis}

Target of the optimization is to find a cost effective and technically safe solution. For the end approval either a qualification analysis report or a final shake table tests can take place, as per agreement with the client.

A possible solution of scenario 1 , as this scenario is described in section 2, is illustrated in Figure 8. A shake table tested base isolation solution (a) which did
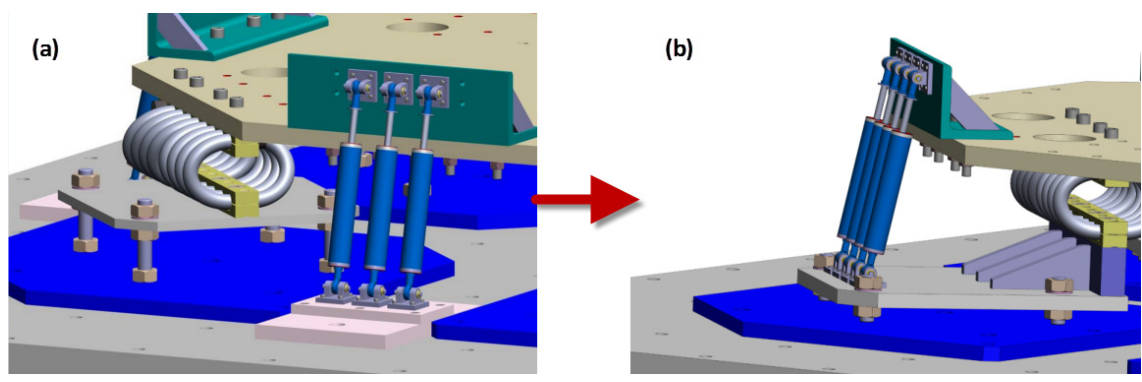

Figure 8: Tested (a) and numerically optimized (b) base isolation solution (source of pictures: Siemens AG). 
not meet the requirement for high seismic, provided the necessary data for the development of a feasible and safe solution (b) which was developed in a finite element analysis software and was cost optimized.

\section{Summary and conclusion}

In this paper, a methodology for qualification of a base isolated electrical high voltage equipment for high seismic requirements has been shown. A traditional approach of sizing and testing was combined with a numerical approach with finite element analysis which shows how to determine a cost optimized and at the same time best performing base isolation solution for a HV circuit breaker. The presented solution is not limited to specific component type or seismic requirements.

The used base isolation principle which uses a combination of wire ropes and viscous damper leads to a significant decoupling from seismic ground motions and to reduced stresses and deformations in the structure of the equipment. Through the variability of size and quantity of used wire ropes and the viscous damper characteristics the base isolation system can be adapted to a wide range of weights with different geometries and mass distribution.

\section{References}

[1] IEEE Recommended Practice for Seismic Design of Substations, IEEE Std 693 ${ }^{\text {TM}}$-2005, IEEE Power Engineering Society, 2006, New York, USA.

[2] Patent no.: 2014E03763 DE/2014P20533 US. 'Invention: Standard Base Isolation System for single supported HV Components based on a combined arrangement of wire rope and viscous dampers through the example of 3AP3 Circuit Breaker base isolation, New Zealand Pole3 project.', 2014.

[3] CSI Analysis Reference Manual - For SAP2000, ETABS, SAFE and CSiBridge, Computers and Structures Inc., 2011, Berkeley, California, USA.

[4] Study of the effectiveness of steel cable dampers for the seismic protection of electrical equipment, F. Paolacci and R. Giannini, The $14^{\text {th }}$ World Conference on Earthquake Engineering, October 12-17, 2008, Beijing, China. 